\title{
Insolvenzanfechtung im bargeldlosen Zahlungsverkehr
}

Eine insolvenzrechtsdogmatische Abhandlung zum Insolvenzanfechtungsrisiko bei Überweisungen und Lastschriften in der Insolvenz des Girokontoinhabers

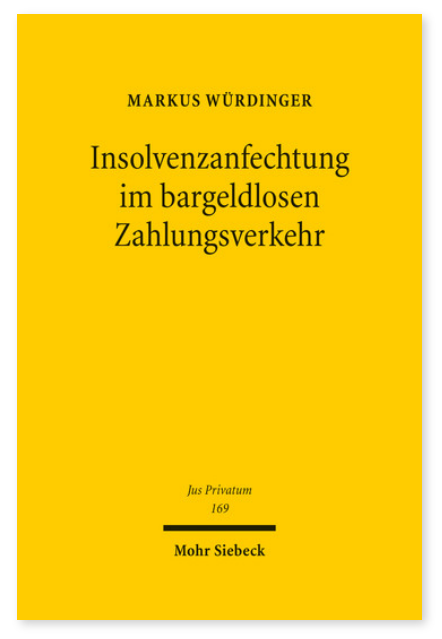

2012. XXIX, 468 Seiten. JusPriv 169

ISBN 978-3-16-152128-7

DOI 10.1628/978-3-16-152128-7

eBook PDF 119,00€

ISBN 978-3-16-152072-3

Leinen $119,00 €$
Das Insolvenzanfechtungsrecht gilt als die »Königsdisziplin des Insolvenzrechts«. Dieses Instrumentarium der vorgreiflichen Haftungsverwirklichung dient der Massemehrung: Durch die Insolvenzanfechtung sollen ungerechtfertigte

Vermögensverschiebungen, durch die das Schuldnervermögen verkürzt wurde, rückgängig gemacht werden. Besondere praktische Bedeutung entfaltet das Insolvenzanfechtungsrecht im Schnittbereich zum Bankrecht. Die induktiv aufgebaute Abhandlung systematisiert die Fallgruppen, die sich bei Überweisungs- und Lastschriftgeschäften in der Insolvenz des Girokontoinhabers ergeben. Das Kreditinstitut agiert dabei sowohl als Kreditgeberin als auch als Zahlungsmittlerin. Markus Würdinger entwickelt auf der Grundlage dieser Doppelfunktionalität eigene Lösungsansätze und formuliert universelle Lehren zum Insolvenzanfechtungsrecht.

Markus Würdinger ist Inhaber des Lehrstuhls für Bürgerliches Recht und Zivilprozessrecht an der Universität Passau.

Jetzt bestellen:

https://mohrsiebeck.com/buch/insolvenzanfechtung-im-bargeldlosen-zahlungsverkehr-9783161521287?no_cache=1

order@mohrsiebeck.com

Telefon: +49 (0)7071-923-17

Telefax: +49(0)7071-51104 